\title{
MJN EFFECT OF AN EDUCATIONAL INTERVENTION ON MOTHERS' KNOWLEDGE, ATTITUDE AND PRACTICE ABOUT PROPER ANTIBIOTIC USE IN A SELECTED FAMILY HEALTH CENTER
}

\author{
Rabab Gad Abd El-Kader ${ }^{1,2 *}$, Hanan Hamed Mohammed ${ }^{1}$ \\ ${ }^{1}$ Department of Community Health Nursing, College of Nursing, Mansoura University, Egypt \\ ${ }^{2}$ College of Nursing, RAK Medical and Health Sciences University, UAE \\ *Corresponding Author's Email: dr_rabab3@yahoo.com
}

\begin{abstract}
Background: Improper antibiotic use is a significant community health issue that contributes to antibiotic resistance. Insufficient mothers' knowledge about the cautious antibiotics use in treating common childhood diseases can end in its misuse. Improving mothers' awareness about correct antibiotic use is the main aspect. The study is aimed to assess the effect of an educational intervention on mothers' knowledge, practice and attitude about proper antibiotic use. Methods: A quasi-experimental design - one group pre-post-test among 130 mothers was carried out in selected family health centers. Baseline knowledge, practice and attitude (preintervention) regarding judicious antibiotic use was assessed using structured interview questionnaire developed by researcher which comprised of socio-demographic data of mother and child, source of knowledge, the mothers' knowledge, subjective practice and their attitude about appropriate antibiotic use. Educational intervention on proper antibiotic use of children was administered after baseline assessment. The effect of this intervention was evaluated using same questionnaire post the intervention and after 3 months. Results: About $41.5 \%$ of the mothers age were from 20 to not more than 35 years. Mothers had poor knowledge about the concept of judicious use of antibiotics, indication of proper antibiotic use, side effect and causes of antibiotic resistance in the pre-test that improved after implementation of the educational session. Health education sessions significantly improved antibiotic-related practice and attitude of the mothers. Conclusion: The health education session about appropriate antibiotic use revealed a major effect in improving the participants' level of awareness, practice and changing attitude about proper use of antibiotic of their children.
\end{abstract}

Keywords: Knowledge; Effect; Practice; Antibiotic Use; Educational Intervention

\section{INTRODUCTION}

Antibiotics are often used to manage infections, but they aren't always the answer. Children are common consumers of antibiotics, and their caregivers play an important role in determining the proper use of antibiotics. Worldwide, young children use antibiotics too much because of their vulnerability to infections, mainly Upper Respiratory Tract Infections (URTIs). Prescription of antibiotics for URTIs is very common practice in pediatrics although there is evidence supporting the viral origin of most of those illnesses. Unnecessary use of antibiotics among children is of special concern in low- and middle-income countries as a result of the higher prevalence of infectious diseases, poor hygiene, sanitation, and public health in these contexts (Dyar et al., 2012; Yu et al., 2014).

WHO (2018) informed that antibiotic resistance is one of the main threats to health worldwide at present. This threat is being speeded up by the systematic misuse and overuse of antibiotics, along with poor infection. Antibiotic resistance is connected with treatment failures, increased mortality and intangible healthcare costs. It can affect anybody, of any age, in any country. Antibiotic resistance happens when bacteria changes as a result of using antibiotics.

WHO (2015a) listed that the development of antibiotic resistance is presently more rapid than the rate 
of evolution of new antibiotics. Responding to this crisis, a global action plan was endorsed at the World Health Assembly in the year 2015. The primary objective of this plan was to improve public awareness and understanding of antibiotic resistance through appropriate communication, education and training.

WHO (2015b) conducted a study on antibiotic use over many countries, regarding the awareness of antibiotics and antibiotic resistance. The findings revealed that widespread public misunderstanding regarding antibiotics and their resistance. It also pointed out the urgent need for improving awareness and understanding of antibiotic resistance.

Various factors have been stated to increase unreasonable antibiotic use among children as; overdoctors' prescription, easy access to antibiotics for selfmedication, and inadequate knowledge among parents about antibiotics (Currie, Lin \& Zhang, 2011). Parents' perceptions and practices regarding the manner of use of medicines have a key outcome on the management of young children ailments. As a community health nurse, it is essential to increase awareness and understanding of antimicrobial resistance through effective communication, education and training to the community specifically the mothers.

Educational interventions have revealed to be valuable in increasing the awareness and changing beliefs and attitudes of the general public about several community health concerns including antibiotic resistance (Alder et al., 2010; Shehadeh, Suaifan \& Hammad, 2016). Numerous studies conducted (Jairoun et al., 2019; Salama et al., 2018), emphasized on the major gaps in antibiotic awareness and practices, which are in turn supporting the growing hazards of antibiotic resistance. Understanding the local public knowledge regarding antibiotics and their resistance development. Along with the recognition of the misconceptions related to them as they play an important role in shaping government policies and campaigns to address this critical issue.

Misunderstanding of antibiotics use among the mother has been commonly delineated to be the core reason for inappropriate use of antibiotics comprising failure to complete treatment, skipping of doses, re-use of remaining medications and overuse of antibiotics. Understanding the judicious use of antibiotics should be promoted among community stakeholders comprising of parents of children, to effectively manage community-based antibiotic resistance (AlAyed, 2019).

Community health nurse play a central role in the reduction of antibiotics misuse among children with URTIS by educating mothers about the significance of correct use of antibiotics, nurses-mothers communication and interactions. Policy change, as: delaying antibiotics prescription for 48 hours which will give the self-limiting conditions time to heal without usage of medications. Health education aids mother to provide a better care to their children with URTIS and improve their quality of lifespan(Vandana, Dipti \& Rajakumari, 2013).

\section{The Study Aim}

To assess the effect of an educational intervention on mothers' knowledge, attitude and practice about proper antibiotic use for their children in a selected family health center.

\section{Research Hypothesis}

Mothers who received educational sessions related to appropriate antibiotic use will have high improvement in knowledge level than pre-test.

Educational- based intervention will be an effective approach for changing mothers' attitude about children antibiotic use.

Mothers who receive educational sessions about appropriate antibiotic use will have satisfactory level of practice than the pre intervention group.

\section{SUBJECT \& METHODS}

\section{Research design}

A quasi-experimental design - one group pre-post test.

\section{Study settings}

Met-Khameis \& Awish - Elhagar Family Health centers, Mansoura District, Dakahalia Governorate, Egypt.

\section{Subject of the study}

Comprised of the mothers who had children less than 6 years old, attended the family health centers for any complains during the study and willing to participate in the study.

\section{Sampling}

Participants were recruited using the convenience sampling technique. One hundred and thirty mothers participated in the study and provided with written informed consent.

\section{Tools of data collection}

Structured interview questionnaire was developed 
after reviewing the related literatures that included the following parts:

Part 1: Socio-demographic characteristics of mother and children such as mothers' age, education level, occupation and child age.

Part II: Source of knowledge about judicious use of antibiotics and antibiotic resistance as media, health care workers, in addition to friends.

Part III: Structured interview questionnaire to assess the mothers' knowledge about concept of antibiotic, indication of proper antibiotic use, side effect and causes of antibiotic resistance. Questions was marked as 1 point for true answer and 0 point for the wrong and do not know. Knowledge scoring categorized as; poor $<50 \%$; fair from $50-<75 \%$; good $\geq 75$.

Part IV: Structured interview questionnaire related to the mothers' subjective practice about appropriate antibiotic use marked as; one for proper and zero for improper practice. Practice scoring categorized as: unsatisfactory $<70 \%$ while satisfactory $\geq 70$.

Part V: Attitude Likert scale: this part designed to assess mothers attitude regarding antibiotic use rated on a 5-point Likert scale scoring; Strongly Agree $(\mathrm{SA})=5$, Agree Slightly $(\mathrm{AS})=4$, Neither agree nor disagree $(\mathrm{NAD})=3$, Disagree Slightly $(\mathrm{DS})=2$, Disagree Strongly $(\mathrm{DS})=1$ for the positive attitudes; while Agree Strongly $(\mathrm{SA})=1$, Agree Slightly $(\mathrm{AS})=2$, Neither agree nor disagree $(\mathrm{NAD})=3$, Disagree Slightly $(\mathrm{DS})=$ 4 , Disagree Strongly (DS) $=5$ for the negative attitudes. For the attitude level score about appropriate antibiotic use: unsatisfactory $<70 \%$ while satisfactory $\geq 70$.

\section{Validity}

Content validity of the questionnaire were conducted by requesting five experts in community health nursing to assess if the questionnaire items are relevant and can properly measure knowledge, practice, and attitude of mothers regarding proper antibiotic use and resistance. All suggested modifications were done along with the experts' feedback on simplicity of sentences and the suitability of the content.

\section{Pilot Study and Reliability of Tools}

A pilot study was directed for 13 of the mothers (around $10 \%$ of the sample size) to examine the applicability of the questionnaires and these mothers were omitted from the study sample. Data used to assess internal consistency reliability which resulted in a
Cronbach's alpha score of 0.92., signifying high reliability.

\section{Educational Intervention}

The intervention comprised of a teaching and discussion session of $20 \mathrm{~min}$, which was delivered with the help of a PowerPoint presentation. The content of the session consisted of information regarding antibiotic use, misuse, side effect and antibiotic resistance. Colored booklet about appropriate use of antibiotic and resistance was constructed after reviewing the literature in simple Arabic language. Five experts were requested for content validity of the booklet and to give their opinion and suggestions. Based on their suggestions, the content was reviewed.

\section{Implementation}

The enrolment of the participants was done on the basis of the study criteria. Preceding to collection of data, the investigator presented her-self and explicated the purpose of the study. A written informed consent was given to the participants. Assessment of mothers' baseline knowledge, practice and attitude (pretest) regarding antibiotics and their resistance by the questionnaire was done for 5-10 minutes. After the baseline assessment, an educational intervention session was explained to the study participants. Effect of the intervention was evaluated directly after the session and follow up after 3 months using the same questionnaire. The dropouts were 17 mothers.

\section{Ethical Consideration}

Formal authorizations were received from the directors of Meet Khamess \& Awish El- Hagar family health centers. The study was initiated after taking ethical approval from Nursing college Research and Ethics Committee. Written consent was attained from the participants. They were reassured about the confidentiality of the information and informed about their rights to refuse involvement or take out at any time.

\section{Statistical Analysis}

The analysis of the data after encoding and input is made using appropriate software package SPSS (Stands for Statistical Product and Service Solutions) version 20. Data were offered by means of descriptive statistics in the arrangement of frequencies, percentage, mean and standard deviation. A Chi-square was used and Pvalue was significant at $\leq 0.05$. 


\section{RESULTS}

Table 1: Distribution of The Study Participants in Relation to Their Socio-Demographic Data

\begin{tabular}{|c|c|c|}
\hline Variables & $\begin{array}{c}\mathbf{N} \\
(130)\end{array}$ & $\%$ \\
\hline \multicolumn{3}{|l|}{ Age of mother (years) } \\
\hline$<20$ & 27 & 20.8 \\
\hline $20-<30$ & 54 & 41.5 \\
\hline $30-35$ & 49 & 37.7 \\
\hline \multicolumn{3}{|l|}{ Age of child (years) } \\
\hline$<$ one & 44 & 33.8 \\
\hline One $-<$ three & 55 & 42.4 \\
\hline$\geq$ three $-<\operatorname{six}$ & 31 & 23.8 \\
\hline \multicolumn{3}{|l|}{ Number of children } \\
\hline One & 19 & 38.0 \\
\hline Two - three & 23 & 46.0 \\
\hline$>$ Three & 8 & 16.0 \\
\hline \multicolumn{3}{|l|}{ L evel of education } \\
\hline Illiterate & 21 & 16.2 \\
\hline Read and write & 45 & 34.6 \\
\hline Diploma & 36 & 27.9 \\
\hline Bachelor & 16 & 12.3 \\
\hline \multicolumn{3}{|l|}{ Job } \\
\hline Worker & 19 & 14.6 \\
\hline Clerk & 43 & 33.3 \\
\hline H ousewife & 68 & 52.3 \\
\hline \multicolumn{3}{|l|}{ Income } \\
\hline $1000-<2000$ & 41 & 31.5 \\
\hline $2000-<3000$ & 58 & 44.6 \\
\hline$\geq 3000$ & 31 & 23.8 \\
\hline \multicolumn{3}{|l|}{ Reason of the visit } \\
\hline Diagnosis & 56 & 43.0 \\
\hline Laboratory investigation & 34 & 26.1 \\
\hline Vaccination & 40 & 30.7 \\
\hline
\end{tabular}

Table 1 clarifies that more than one-third (41.5\%) of mothers were in the age group of 20 - 30 years old, more than one third $(34.6 \%)$ were able to read and write and more than half $(52.3 \%)$ were housewives. More than one third $(42 \%)$ of children were aged from one year to three years, about $42.3 \%$ of mothers had 2 to 3 children and $43 \%$ came to the Family Health Center for diagnosis. All the participants were living in rural area. As regards to family income around half (44.6\%) ranged from 2000 to less than 3000 pounds.

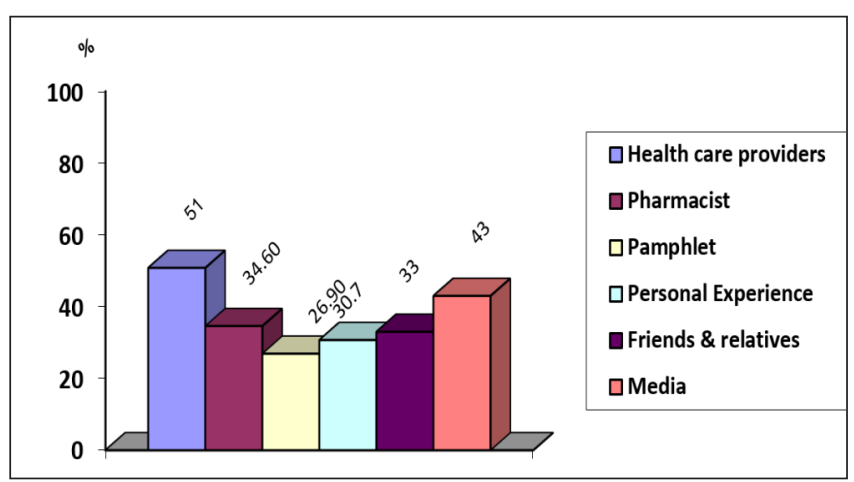

Figure 1: Distribution of The Study Participants in Relation to Their Source of Information about Judicious Use of Antibiotics for Children

On the subject of source of information Figure 1 exhibits that, more than half $(51 \%)$ of the study participants were informed by health care providers. Around one-third $(34.6 \%),(30.7 \%),(33 \%)$ were reported to pharmacist, personal experience, friends and relatives respectively. Media represented $43 \%$ cases, while more than one - fourth $(26.9 \%)$ mentioned pamphlet as a source of information.

Distribution of The Study Participants in Relation to Their Pre- Post and Follow Up Level of Knowledge about Antibiotic Use among Children

\begin{tabular}{|c|c|c|c|c|c|c|c|c|c|c|}
\hline \multirow[t]{2}{*}{ Items } & \multicolumn{3}{|c|}{ Pre (130) } & \multicolumn{3}{|c|}{ Post (130) } & \multicolumn{3}{|c|}{ Follow up (110) } & \multirow{2}{*}{$\begin{array}{c}X^{2} \\
P \text { - Value }\end{array}$} \\
\hline & $\begin{array}{r}\text { Poor } \\
\text { N\% }\end{array}$ & $\begin{array}{l}\text { Fair } \\
\text { N\% }\end{array}$ & $\begin{array}{c}\text { Good } \\
\text { N\% }\end{array}$ & $\begin{array}{c}\text { Poor } \\
\text { N\% }\end{array}$ & $\begin{array}{l}\text { Fair } \\
\text { N\% }\end{array}$ & $\begin{array}{c}\text { Good } \\
\text { N\% }\end{array}$ & $\begin{array}{c}\text { Poor } \\
\text { N\% }\end{array}$ & $\begin{array}{l}\text { Fair } \\
\text { N\% }\end{array}$ & $\begin{array}{c}\text { Good } \\
\text { N\% }\end{array}$ & \\
\hline Concept of judicious use of antibiotics & $\begin{array}{c}44 \\
33.8\end{array}$ & $\begin{array}{c}9 \\
7.0\end{array}$ & $\begin{array}{c}77 \\
59.2\end{array}$ & $\begin{array}{c}4 \\
3.0\end{array}$ & $\begin{array}{c}6 \\
4.6\end{array}$ & $\begin{array}{l}120 \\
92.4\end{array}$ & $\begin{array}{c}3 \\
2.8\end{array}$ & $\begin{array}{c}15 \\
13.6\end{array}$ & $\begin{array}{c}92 \\
83.6\end{array}$ & $\begin{array}{r}74.57 \\
<0.001\end{array}$ \\
\hline Symptoms that require antibiotics use & $\begin{array}{c}89 \\
68.5 \\
\end{array}$ & $\begin{array}{c}22 \\
16.9 \\
\end{array}$ & $\begin{array}{c}19 \\
14.6\end{array}$ & $\begin{array}{c}3 \\
2.4 \\
\end{array}$ & $\begin{array}{c}13 \\
10.0 \\
\end{array}$ & $\begin{array}{c}114 \\
87.6\end{array}$ & $\begin{array}{c}22 \\
20.0\end{array}$ & $\begin{array}{c}9 \\
8.2\end{array}$ & $\begin{array}{c}79 \\
71.8\end{array}$ & $\begin{array}{r}169.03 \\
<0.001\end{array}$ \\
\hline $\begin{array}{l}\text { Infection that require use of } \\
\text { antibiotics }\end{array}$ & $\begin{array}{c}88 \\
67.7\end{array}$ & $\begin{array}{c}23 \\
17.7\end{array}$ & $\begin{array}{c}19 \\
14.6\end{array}$ & $\begin{array}{c}4 \\
3.0\end{array}$ & $\begin{array}{c}22 \\
17.0\end{array}$ & $\begin{array}{c}104 \\
80.0\end{array}$ & $\begin{array}{c}7 \\
6.4\end{array}$ & $\begin{array}{c}38 \\
34.5\end{array}$ & $\begin{array}{c}65 \\
59.1\end{array}$ & $\begin{array}{c}192.81 \\
<0.001\end{array}$ \\
\hline Side effect & $\begin{array}{c}91 \\
70.0\end{array}$ & $\begin{array}{c}19 \\
14.6 \\
\end{array}$ & $\begin{array}{c}20 \\
15.4 \\
\end{array}$ & $\begin{array}{c}32 \\
24.6\end{array}$ & $\begin{array}{c}24 \\
18.5 \\
\end{array}$ & $\begin{array}{c}74 \\
56.9\end{array}$ & $\begin{array}{c}24 \\
21.8 \\
\end{array}$ & $\begin{array}{c}65 \\
59.1\end{array}$ & $\begin{array}{c}21 \\
19.1 \\
\end{array}$ & $\begin{array}{r}137.94 \\
<0.001 \\
\end{array}$ \\
\hline Antibiotic resistance causes & $\begin{array}{c}96 \\
73.8\end{array}$ & $\begin{array}{c}17 \\
13.1\end{array}$ & $\begin{array}{c}17 \\
13.1\end{array}$ & $\begin{array}{c}9 \\
7.0\end{array}$ & $\begin{array}{c}27 \\
20.7\end{array}$ & $\begin{array}{c}94 \\
72.3\end{array}$ & $\begin{array}{c}2 \\
1.8\end{array}$ & $\begin{array}{c}22 \\
20.0\end{array}$ & $\begin{array}{c}86 \\
78.2\end{array}$ & $\begin{array}{l}204.10 \\
<0.001\end{array}$ \\
\hline Antibiotic resistance prevention & $\begin{array}{r}124 \\
95.4\end{array}$ & $\begin{array}{c}2 \\
1.6 \\
\end{array}$ & $\begin{array}{c}4 \\
3.0\end{array}$ & $\begin{array}{c}32 \\
24.6\end{array}$ & $\begin{array}{c}9 \\
7.0 \\
\end{array}$ & $\begin{array}{c}89 \\
68.4\end{array}$ & $\begin{array}{c}15 \\
13.6\end{array}$ & $\begin{array}{c}7 \\
6.4\end{array}$ & $\begin{array}{l}88 \\
80\end{array}$ & $\begin{array}{r}198.70 \\
<0.001\end{array}$ \\
\hline
\end{tabular}


Table 2 represents the knowledge level of the study sample; where $59.2 \%$ had good knowledge about the concept of judicious antibiotics use pre educational intervention, that improved after the intervention and follow-up $(92.4 \%, 83.6 \%)$ respectively with a statistically significant difference. Only $15.4 \%$, $14.6 \%, 13.1 \%$ and $(3.0 \%$ had good knowledge about side effect, type of infection, indication of antibiotic used, antibiotic resistance causes and prevention before the intervention respectively. This improved to $56.9 \%, 80 \%, 87.6 \%, 72.3 \%$ and $68.4 \%$ respectively after the intervention with statistically significant difference $(P<0.001)$.

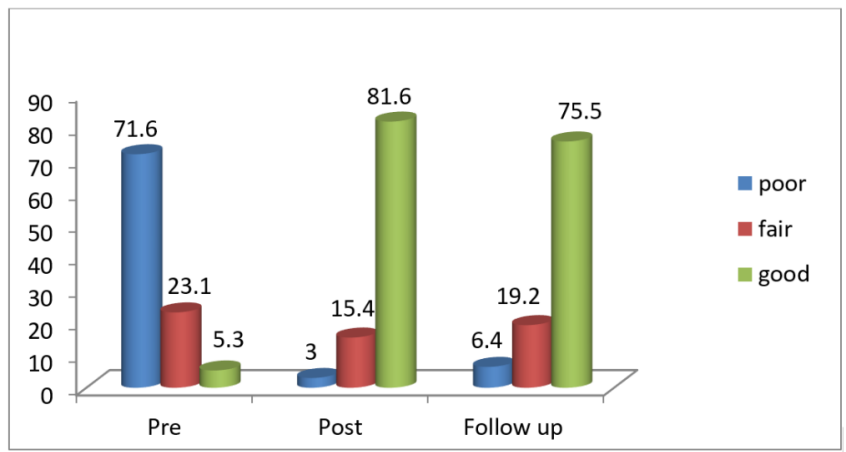

Figure 2: Pre-Post and Follow Up Knowledge Level of The Study Participants Regarding Appropriate Antibiotic Use

In relation to the level of knowledge of the study participants Figure 2 exemplifies that, the minority $(5.3 \%)$ had good knowledge about antibiotic use among children during pre-test which enriched significantly after the intervention and follow up (81.6\%), (75.5\%) respectively with a highly statistically significant difference $(p<0.001)$ amongst the groups.

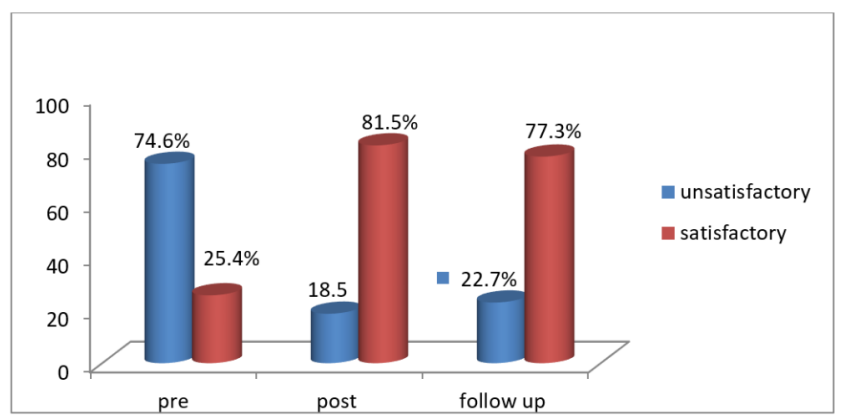

Figure 3: Pre-Post and Follow Up Subjective Practice Level of The Study Participants Regarding Appropriate Antibiotic Use

As to subjective practice level of the study participants Figure 2 elucidates that, only one quarter
(25.4\%) of mothers had satisfactory subjective practice about appropriate antibiotic use among children during pre-test which increased to the majority $(81.5 \%)$ after intervention. On the subject of the findings of the follow up the improvement was decreased to $77.3 \%$. There was a highly statistically significant difference $(p=0.001)$ amongst the study groups.

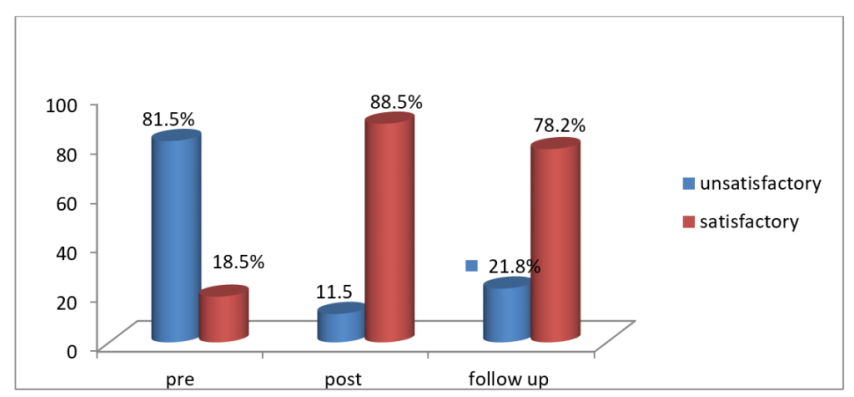

Figure 4: Pre-Post and Follow Up Attitude Level of The Study Participants Regarding Appropriate Antibiotic Use

With reference to attitude level of the study participants Figure 2 exemplifies that, only $18.5 \%$ of mothers had satisfactory attitude about appropriate antibiotic use among children before the intervention that increased the majority $(88.5 \%)$ after intervention, and $78.2 \%$ after 3 months follow up. There was a highly statistically significant difference $(p=0.001)$ between the attitude score of the study groups.

\section{DISCUSSION}

Incorrect and extreme uses of antibiotics arise from a complex interaction between several aspects linked to parent's knowledge and attitude, as erroneous habits of self-medication; non-compliance; parents' experience with antibiotics and incomplete parent education (Zyoud et al., 2015). Health education provides a great opportunity to individuals to learn about the essentials for health, it helps them to take steps to improve the quality of their wellbeing (McKenzie, Neifer \& Thackeray, 2009). Therefore, health education can significantly improve mothers' knowledge and practices regarding the appropriate use of antibiotics for their children.

Unnecessary use of antibiotics exposes the community to unwarranted medication use and contributes to the development of antimicrobial résistance. Accordingly, enhancing mothers' knowledge about antibiotic resistance and appropriate use by educational interventions has been strongly advocated and also mothers' education is an integral component to 
promote judicious antibiotic use (Vaz et al., 2015). The present study aimed to assess the effect of educational intervention on mothers' knowledge, practice and attitude about appropriate antibiotic use for their children.

The present study showed that the baseline knowledge of the study participants concerning indication of antibiotic use, proper antibiotic use, causes of antibiotic resistance and prevention was low before the intervention which improved after the educational sessions and during follow up with highly statistically significant differences $P \leq 0.001$. Accordingly, this study finding may be contributed to the deficiency of educational messages in the mass media about appropriate use of antibiotic along with poor awareness about the worth of health.

The present study finding revealed that, there was improvement of mother's overall level of knowledge about appropriate antibiotic use after the educational sessions at the immediate and the follow-up with highly statistical significance differences. This may be as a result of using the simplest language during the educational session, readiness of the mothers who had children less than five years to know about indication of antibiotic use and the clarity and consistency of the educational materials. These findings are consistent with Shehadeh, Suaifan \& Hammad, (2016) conducted on Jordan that reported that overall knowledge about appropriate antibiotic use, improved after the intervention.

In relation to the mother's knowledge about antibiotic resistance. The study findings revealed that more than half of mothers were not aware about common habits contributing to antibiotic therapy failure including recurrent use of antibiotic before the sessions that improved after the intervention immediately and followup. The present finding was in the same line with the study conducted by Trepka et al., (2013) on 729 parents at Northern Wisconsin to assess changes in knowledge and awareness regarding antibiotic resistance and appropriate antibiotic use after community-wide educational interventions who reported that overall knowledge about antibiotic resistance of parent better after the intervention than before.

Moreover, the present study finding was consistent with Rabbani et al., (2020) who assess the awareness of people living in United Arab Emirates regarding antibiotics and antibiotic resistance and reported that the intervention led to significant improvement in their knowledge of antibiotics and resistance.
There was improvement of mother's knowledge about antibiotic resistance after implementation of the educational intervention with a highly statistical significance differences due to the effect of the session that used multifaceted educational material and modalities. This provided the greatest opportunities to reach different audiences and have been shown to improve knowledge about antibiotic resistance. One of the key areas in the control of antibiotic resistance is the change in the behavior of consumers and providers of antibiotics and strategies that recommend education of the public to promote appropriate antibiotic use.

The present study finding revealed that there were satisfactory practice score of mothers regarding appropriate antibiotic use after implementation of educational sessions with highly statistical significance differences comparing pre-test implementation due to the effect of the session that leads to improve practice of mother to use antibiotic properly and reduced incidence of inappropriate use. This study finding is consistent with Kandeel et al., (2019) who promoted appropriate antibiotic use for acute respiratory infections in a district in Egypt and concluded that improved practice level after educational session, and they reported reduction of unnecessary use of antibiotic.

As regards to mothers attitude score towards appropriate antibiotic use, the present study finding showed that the mothers had unsatisfactory attitude score regarding appropriate antibiotic use before implementation of educational sessions while immediate and at the follow- up, there were satisfactory attitude score about appropriate antibiotic use after implementation of educational intervention with highly statistically significance differences. The present study finding was in the same line with Taylor, Kwan-Gett \& McMahon (2019) regarding the effectiveness of educational materials in improving the attitudes of parents of young children and about the judicious use of antibiotics. They reported that overall attitude score of mothers were unsatisfactory before the educational program and there was improvement of attitude score than before intervention.

The hypothesis of the study as attained from the present study findings showed that mothers who joined the sessions about appropriate antibiotic use became more aware post educational sessions than before, they demonstrated proper practice and positive change in the attitude towards children antibiotic use. 


\section{CONCLUSION}

The minority of the study participants had knowledge regarding appropriate antibiotic use, indication of antibiotic use and causes of antibiotic resistance. The health educational session revealed a major effect in increasing the participants' level of knowledge and modifying practice and attitude about the judicious use of antibiotics.

\section{Recommendations}

- Health education about appropriate antibiotic use should be approved as a part of the preventive services obtained to the mothers.

- Mass media networks should be used to publicize the data about the appropriate antibiotic use and child health.

- Health education campaign must be conducted in the countryside and urban areas to increase the mothers' awareness about proper antibiotic use, antibiotic resistance and its effect on child health.

\section{Conflict of Interests}

The authors declare that they have no conflict of interest.

\section{ACKNOWLEDGEMENT}

The authors are thankful to all mothers who participated in the study.

\section{REFERENCES}

Al-Ayed. \& M. S. Z. Parents' knowledge, attitudes and practices on antibiotic use by children. Saudi Journal of Medicine \& Medical Sciences, 7(2), pp 93.

Alder, S., Wuthrich, A., Haddadin, B., Donnelly, S., Hannah, E. L., Stoddard, G. \& Samore, M. (2010). Community intervention model to reduce inappropriate antibiotic use. American Journal of Health Education, 41(1), pp 20-28.

Currie, J., Lin, W. \& Zhang, W. (2011). Patient knowledge and antibiotic abuse: Evidence from an audit study in China. Journal of health economics, 30(5), pp 933-949.

Dyar, O. J., Hoa, N. Q., Trung, N.V., Phuc, H.D., Larsson, M., Chuc, N.T. \& Lundborg, C.S. (2012). High prevalence of antibiotic resistance in commensal Escherichia coli among children in rural Vietnam. BMC infectious diseases, 12(1), 92 .

Jairoun, A., Hassan, N., Ali, A., Jairoun, O. \& Shahwan, M. (2019). Knowledge, attitude and practice of antibiotic use among university students: a cross sectional study in UAE. BMC public health, 19(1), 518.

Kandeel, A., Palms, D. L., Afifi, S., Kandeel, Y., Etman, A., Hicks, L. A. \& Talaat, M. (2019). An educational intervention to promote appropriate antibiotic use for acute respiratory infections in a district in Egypt-pilot study. BMC Public Health, 19(3), 498.

McKenzie, j., Neifer, B. \& Thackeray, R (2009) planning, implementing and evaluating health promotion programme 5th edition. San Francisco, CA Pearson Education, Inc.

Rabbani, S.A., Sridhar, S.B., Abazer, D., Ahmed, H.S., Usman, H.A., Mahtab, A. \& El-Dahiyat, F. (2020). Impact of community-based educational intervention on antibiotic use and resistance awareness among the people living in Ras A1 Khaimah, United Arab Emirates. Journal of Pharmaceutical Health Services Research, 11(3), pp 197-204.

Sa'ed, H.Z., Taha, A.A., Araj, K.F., Abahri, I.A., Sawalha, A.F., Sweileh, W.M., Awang, R. \& Al-Jabi, S.W. (2015). Parental knowledge, attitudes and practices regarding antibiotic use for acute upper respiratory tract infections in children: a cross-sectional study in Palestine. BMC pediatrics, 15(1), pp1-9.

Salama, R.A., Bader, K.N., Rahmen, A.S. \& Hashmi, F. (2018). Parents Knowledge, attitude and practice of antibiotic use for upper respiratory tract infections in children: a cross-sectional study in Ras Al khaimah, United Arab Emirates. Epidemiology, Biostatistics and Public Health, 15(4).

Shehadeh, M., Suaifan G. \& Hammad, E. (2016). Active educational intervention as a tool to improve safe and appropriate use of antibiotics. Saudi Pharmaceutical Journal, 24, pp 611-615. 
Taylor, J.A., Kwan-Gett, T.S.C. \& McMahon, E.M. (2003). Effectiveness of an educational intervention in modifying parental attitudes about antibiotic usage in children. Pediatrics, 111(5), pp e548-e554.(2019). Effectiveness of an educational intervention in modifying parental attitudes about antibiotic usage in children. Pediatrics. 111: E548-54.

Trepka, M.J., Belongia, E.A., Chyou, P.H., Davis, J.P. \& Schwartz, B. (2001). The effect of a community intervention trial on parental knowledge and awareness of antibiotic resistance and appropriate antibiotic use in children. Pediatrics, 107(1), pp e6-e6.

Vandana, C., Dipti, Y. S. \& Rajakumari, S. D. (2013). Effectiveness of URTI Preventive Education Programme on Recovery of Children and Practice of Caregivers. IOSR Journal of Nursing and Health Science; 2(2):31-35.

Vaz, L. E., Kleinman, K. P., Lakoma, M. D., Dutta-Linn, M. M., Nahill, C., Hellinger, J. \& Finkelstein, J. A. (2015). Prevalence of parental misconceptions about antibiotic use. Pediatrics, 136(2), pp 221-231.

World Health Organization (WHO) (2018). Antimicrobial Resistance [Internet]. Retrieved from: https://www.who.int/en/news-room/fact-sheets/detail/antimicrobial-resistance

World Health Organization (WHO) (2015a). Global Action Plan on Antimicrobial Resistance [Internet]. Retrieved from: https://www.who.int/antimicrobial-resistance/publications/global-action-plan/en/

World Health Organization (WHO) (2015b). Antibiotics Resistance. Multi-country public awareness survey. World Health Organization: Geneva, Switzerland, 59, ISBN 9789241509817.

Yu, M., Zhao, G., Lundborg, C.S., Zhu, Y., Zhao, Q. \& Xu, B. (2014). Knowledge, attitudes, and practices of parents in rural China on the use of antibiotics in children: a cross-sectional study. BMCInfectious Diseases, 14(1), pp112. 